\title{
Influence of Small Amphiphiles on Aqueous Dispersions of $\beta$-Lactoglobulin A and Bovine Serum Albumin: (1) Intermolecular Interactions
}

\author{
Zahur Z. Haque ${ }^{*}$, Guichard L. Bohoua ${ }^{2}$ \\ ${ }^{1}$ Department of Food Science, Nutrition and Health Promotion, Mississippi State University, Starkville, USA \\ ${ }^{2}$ Ecole des Sciences de la Nature Centre, Universitaire d'Abobo Adjame Abidjan, Abidjan, Cote d'Ivoire \\ Email: ${ }^{*}$ h50msstate.edu
}

Received 12 June 2015; accepted 20 September 2015; published 23 September 2015

Copyright (C) 2015 by authors and Scientific Research Publishing Inc.

This work is licensed under the Creative Commons Attribution International License (CC BY).

http://creativecommons.org/licenses/by/4.0/

(c) (i) Open Access

\section{Abstract}

Hydrophilic and hydrophobic $(\varphi)$ interactions among amphiphiles play critical roles in interfacial properties of proteins and other smaller amphiphiles and affect the creation and stability of foams and emulsions in food systems. Contribution of small amphiphiles on $\mathrm{H}$-bonding and hydrophobic $(\varphi)$ interactions at a model interface comprising of a water-hydrophobized surface interface as reflected by contact angle $(\theta)$ of fatty acid free bovine serum albumin (FAF-BSA), bovine serum albumin (BSA), and $\beta$-lactoglobulin variant A ( $\beta$-LGA) was investigated. Amphiphiles were used with either protein in neutral water or $\alpha$-bromonaphtalene $(\alpha-\mathrm{BrN})\left(22^{\circ} \mathrm{C}\right)$ to obtain $\theta-\mathrm{H}_{2} \mathrm{O}$ and $\theta$ - $\alpha$ - $\mathrm{BrN}$ measurements, respectively. $\theta$ - $\alpha$-BrN reflected influence of $\varphi$-interactions on $\theta$ since $\alpha$-BrN molecules do not partake significantly in $\mathbf{H}$-bonding. Ionic nature of the amphiphiles had no significant effect. Dramatic difference was between zwitterionic Z8 and Z12. At 1\%, Z8 significantly increased H-bonding in BSA and $\beta$-LGA by $26 \%$ and $55 \%$, respectively, whereas $\mathrm{Z12}$, which is more hydrophobic, decreased it by $50 \%$ and $21 \%$. At the same concentration, $\varphi$-interactions were enhanced by Z8 for BSA by $37 \%$ and by all amphiphiles except Z12 for FAF-BSA.

\section{Keywords}

Contact Angle, Hydrogen Bonding, Hydrophobic Interactions, Whey

\section{Introduction}

Amphiphiles are surface active molecules that are characterized in solution by their ability to populate interfaces *Corresponding author.

How to cite this paper: Haque, Z.Z. and Bohoua, G.L. (2015) Influence of Small Amphiphiles on Aqueous Dispersions of 8-Lactoglobulin A and Bovine Serum Albumin: (1) Intermolecular Interactions. Food and Nutrition Sciences, 6, $1126-1133$. http://dx.doi.org/10.4236/fns.2015.612117 
and reduce surface energy [1]. When a low concentration is present in a system, these surface-active agents (surfactants) have the ability to influence surface energy. Small amphiphiles play major roles in systems where the phase area boundary is so large relative to volume of the system that a substantial fraction of total mass of the system is present at boundaries (e.g., in emulsions and colloids). This is particularly true when the phenomena occurring at phase boundaries are so unusual relative to the bulk phase interactions that interfacial processes determine the entire behavior of the system. Therefore, it is necessary to understand the causes of this abnormal behavior of matter at the interfaces and the variables that affect this behavior in order to predict and control emulsification, foaming, and to some extent, gelation in food systems [2].

Surface-active agents such as emulsifiers and most food proteins have a molecular structure consisting of distinctly separate hydrophobic and hydrophilic zones. Presence of such hydrophobic zones in the interior of water causes distortion of its structure thus increasing energy of the system. Consequently, less work is needed to expel these zones compared to water molecules to the surface or interface resulting in increased surface activity of these agents [3]. Thus, their presence and size decreases work needed to create unit surface area; a phenomenon essential for foam and emulsion making. Conversely, the hydrophilic zones such as ionizable side-chain residues of proteins, peptides or polar head-groups or surfactants, prevents complete expulsion from solvent [4].

We have reported that solid-liquid (SL) contact angle measurements of a sessile drop, of various amphiphile containing dispersions, on a uniformly hydrophobized glass surface, were statistically comparable to the surface activity of the amphiphiles determined by other standard methods [5]. Additionally, a recent study involving adsorption isotherms of globular proteins with molecular weights spanning 10 - $1000 \mathrm{kDa}$ confirmed that interfacial energetics of protein adsorption to a hydrophobic solid/aqueous-buffer (SL) interface are not fundamentally different than adsorption to the water-air (liquid-vapor) interface [6] as in food foams. The surface activity of protein dispersions is the result of a balance between repulsive and attractive forces.

Van der Waals attractions have been extensively studied in various systems [7] [8]. Van Oss reconsidered the importance of the attractive forces in light of the Lifshitz theory [9]. Forces accounting for the surface energy are short range, i.e., $<1 \mathrm{~nm}$ (H-bonding) forces and Lifshitz Van der Waals long range, i.e., $<100 \mathrm{~nm}$ (i.e. hydrophobic) $(\varphi)$ interactions. Both components of surface energy can be derived from contact angle $(\theta)$ measurements using two or more well characterized liquids and with the help of the extended Young equation [9] [10]. When $\alpha$-bromonaphtalene $(\alpha-\mathrm{BrN})$ is used as solvent, molecules do not interact with each other via hydrogen bonds to any significant degree. As a result, surface energy as reflected by $\theta$ of sessile drop of a dispersion in $\alpha$-BrNdoes not include the SR contribution.

In this research, we used the sessile drop SL contact angle method [5] to investigate the effect of cationic, anionic, nonionic, and several zwitterionic amphiphiles on the above mentioned interfacial forces in aqueous dispersions of functionally important globular proteins of whey. Bovine serum albumin (BSA) and $\beta$-lactoglobulin A were used. $\beta$-Lactoglobulin was chosen since it is the predominant whey protein and strongly influences the functionality of whey based ingredients [11]. The $\mathrm{A}$ variant ( $\beta$-LGA), which differs from the $\mathrm{B}$ variant (Gly64Asp and Ala118Val) [12] was chosen since it has a greater tendency to self-associate [13]. Bovine serum albumin (BSA) is a large $(66 \mathrm{kD})$ globular whey protein that, though small in presence (5\% of total whey proteins), is important from a food functionality point of view [14]. The fatty acid free version of BSA (FAF-BSA) was used to determine the effect of delipidation of BSA. The subsequent article in this series looks at the influence of the same amphiphiles on the surface and energy and emulsifying properties of the same proteins [15].

\section{Materials and Methods}

\subsection{Materials}

$\gamma$-Methacryloxypropyltrimethoxysilane (silane) (cat\#M6514), sodium dodecyl sulfate (SDS) (cat\#L6026), tetradodecyltrimethyl ammonium bromide (TDTM) (cat\#T4762), bovine serum albumin (BSA) (Fraction V Powder, cat\#A4503) and its essentially fatty acid free form (FAF-BSA) (prepared from same BSA, cat\#A6003), $\beta$ lactoglobulin A ( $\beta$-LGA) (cat\#L-7880), and imidazole (cat\#I-0125) were obtained from Sigma Chemical Company, St. Louis, MO. $\alpha$-Bromonaphtalene $(\alpha-\mathrm{BrN})($ cat\#18,364-4) was from Aldrich, Milwaukee, WI. N-octyl-N, Ndimethyl-3-ammonio-1-propanesulfonate (Z8) (cat\#693019), N-dodecyl-N,N-dimethyl-3-ammonio-1-propa-nesulfonate (Z12) (cat\#693015), polyoxyethylene glycol tert-octylphenyl ether $\left(\mathrm{C}_{8} \mathrm{H}_{17} \mathrm{C}_{6} \mathrm{H}_{4} \mathrm{O}\left(\mathrm{CH}_{2} \mathrm{CH}_{2} \mathrm{O}\right)_{9.5} \mathrm{H}\right)(\mathrm{TX} 100)$ (cat\#648463), and 3[(3 cholaminodopropyl) dimethyl ammonio]-1 propane sulfonate (CHAPS) (Cat\#220-201) were from Calbiochem, San Diego, CA (Figure 1). Optical grade borosilicate square cover glasses (size $25 \times 25$ 

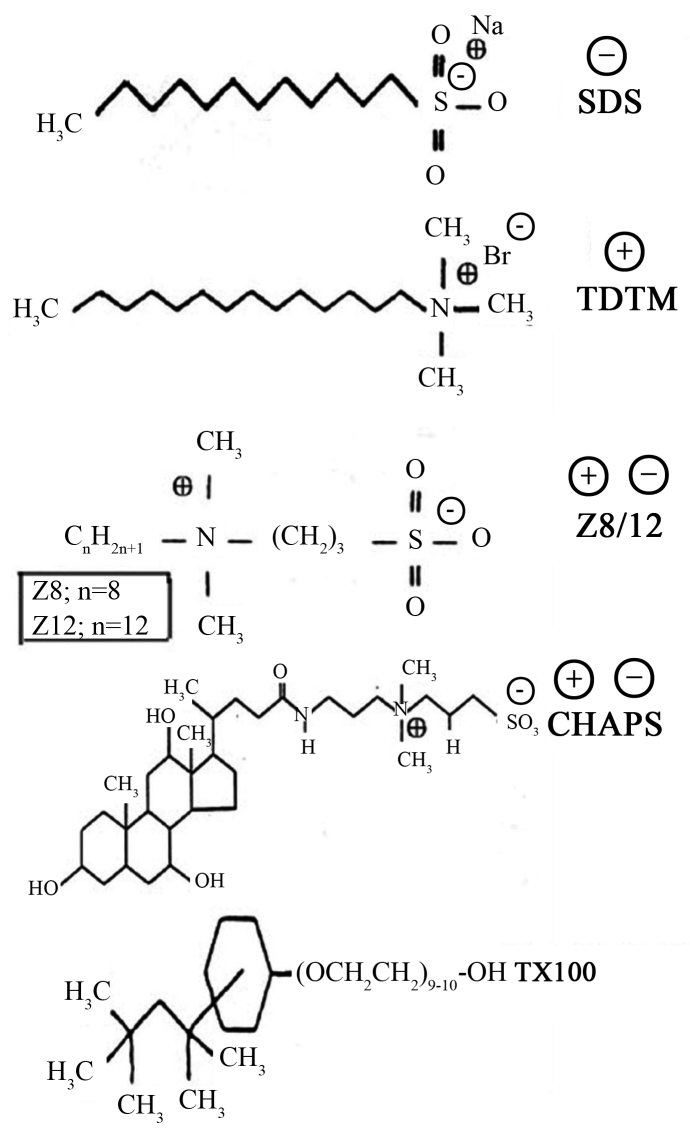

Figure 1. Chemical structures of surfactants used in the study. Abbreviations are as follows: TDTM is cationictetradodecyltrimethyl ammonium bromide, SDS is anionic sodium dodecyl sulfate, Z8 is zwitterionic N-octyl-N,Ndimethyl-3-ammonio-1-propanesulfonate, Z12 is zwitterionic $\mathrm{N}$-dodecyl-N,N-dimethyl-3-ammonio-1-propanesulfonate, CHAPS is zwitterionic 3[(3 cholaminodopropyl) dimethyl ammonio]-1 propane sulfonate, and TX100 is nonionic; polyoxyethylene glycol tert-octylphenyl ether

$\left(\mathrm{C}_{8} \mathrm{H}_{17} \mathrm{C}_{6} \mathrm{H}_{4} \mathrm{O}\left(\mathrm{CH}_{2} \mathrm{CH}_{2} \mathrm{O}\right)_{9.5} \mathrm{H}\right)$. The "n" for $\mathrm{Z8}$ was 8 whereas for $\mathrm{Z} 12$ it was 12 .

mm, thickness 0.13 - $0.17 \mathrm{~mm}$ ) (cat\#12-542C) were purchased from Fisher scientific, Fair Lawn, N J. Double glass distilled deionized water and chromic acid were freshly prepared for all experiments. All other reagents were analytical grade.

\subsection{Methods}

Protein dispersions. Proteins were dispersed (final concentration $1 \%$, w/v) by vortexing in double glass distilled water or $\alpha$-BrN at $22^{\circ} \mathrm{C}$. Surfactants were added to aliquots of the protein dispersions to obtain desired surfactant concentrations of 0 (nil) (control), 1\%, 2\%, and $4 \%$ (w/w).

Determination of $\theta$. The $\theta$ was determined on hydrophobized glass surface as described earlier [5]. In order to prepare glass covers of uniform surface hydrophobicity, the pre-cleaned (with chromic acid) covers were dipped in silane (16 h), dried in vacuo in bell jars at $22^{\circ} \mathrm{C}$ and brought to uniform level of surface dehydration by storing in the evacuated jar over phosphorus pentoxide for $16 \mathrm{~h}$ prior to use. A diamond-ground syringe needle (Kayeness, Inc., Honey Brook, PA.) was used to generate surfactant dispersion droplets $(\sim 50 \mu \mathrm{L})$ of uniform size on the silinated cover glasses. The $\theta-\mathrm{H}_{2} \mathrm{O}$ and $\theta-\alpha$ - $\mathrm{BrN}$ measurements of the sessile droplets of dispersions 
were determined immediately $(<10 \mathrm{sec}$ ) by taking the tangent of the drop with the uniformly hydrophobized glass cover placed in the path of a beam of light from a tungsten source. Measurements were recorded with a small telescope with cross-hairs attached to a goniometer (model D-1060, Kayeness, Inc., Honey Brook, PA). The projection system consisted of a $40 \times$ magnifier, a semi-circular viewing screen, a rotatable protractor $\left(360^{\circ}\right)$ for reading the contact angle and a focusing system. At least three readings were recorded for each concentration of a given amphiphile and means were tabulated.

Statistical analysis. A completely randomized design with three replications was utilized to evaluate the effect of the surfactants and their concentration on $\theta$ of the proteins on the hydrophobized surface. Three samples were taken per replication for each treatment. The data were analyzed using the general linear models (PROCGLM) procedure. The means were separated using Fisher's protected least significance test at $(\mathrm{p}<0.05)$ [16]. The statistical analysis was conducted with SAS version 8.1 [17].

\section{Results and Discussion}

The effect of the surfactants (Figure 1) on $\theta$ varied between the proteins and among surfactants for each protein (Figure 2 and Figure 3). In case of FAF-BSA, contribution of $\mathrm{H}$-bonding, as reflected by the $\theta-\mathrm{H}_{2} \mathrm{O}$ measurements, decreased markedly when combined with all surfactant except zwitterionic Z8 which was the smallest

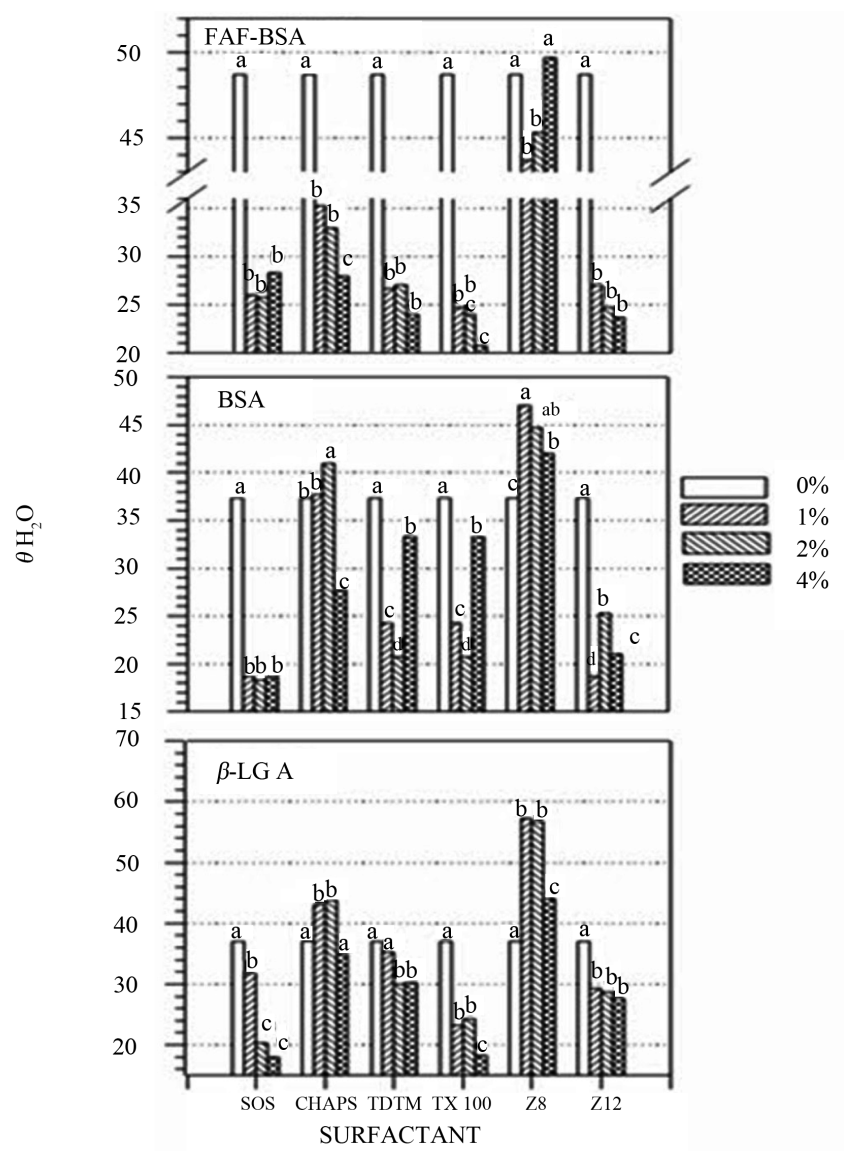

Figure 2. Contact angle measurements of protein dispersions using pure water $\left(\theta-\mathrm{H}_{2} \mathrm{O}\right)$ as the solvent. The $\mathrm{x}$-axis represents the surfactants and abbreviations are elaborated in the legend for Figure 1. FAF-BSA, BSA and $\beta$-LGA are fat free bovine serum albumin, bovine serum albumin and $\beta$-lactoglobulin variant $\mathrm{A}$, respectively. $\mathrm{Y}$-axis is $\theta-\mathrm{H}_{2} \mathrm{O}$ in degrees. Dissimilar alphabets over bars for the same protein and surfactant indicates concentration dependent' statistical significance $(\mathrm{p}<0.05 \%)$. All experiments were carried out at a surfactant to protein weight ratio of $0 \%, 1 \%, 2 \%$, and $4 \%$ at $\mathrm{pH} 7$ as indicated in the legend. 


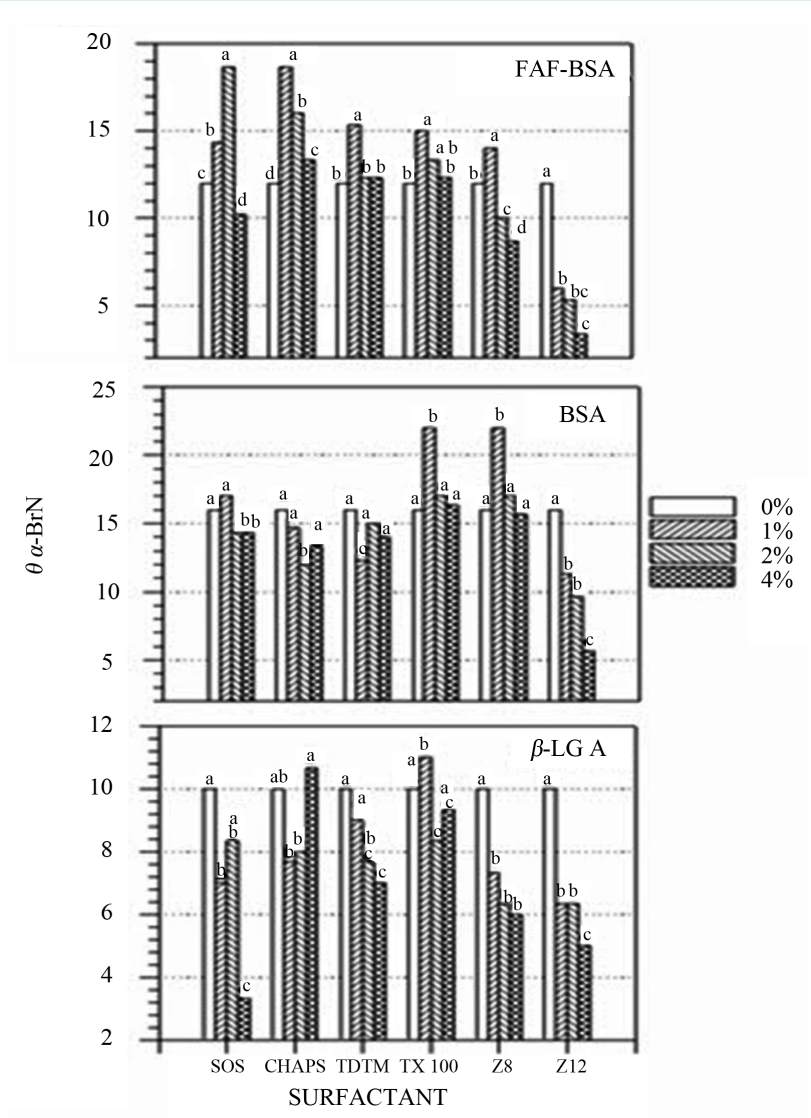

Figure 3. Contact angle measurements of protein dispersions using pure $\alpha$-bromonaphthalene $(\theta-\alpha$-BrN) as the solvent. All abbreviations, explanation of axes, legend description, and statistical notations are as explained in the legend for Figure 2.

surfactant tested (Figure 1). The significant decrease of $\theta-\mathrm{H}_{2} \mathrm{O}$ as a percentage of the control at the least surfactant usage level of $1 \%(\mathrm{w} / \mathrm{w})$ was in the order; TX100 (50\%) > SDS (47\%) > TDTM (46\%) > Z12 (45\%) > CHAPS (28\%) > Z8 (11\%). In all proteins, $\mathrm{Z} 8$ gave the highest $\theta-\mathrm{H}_{2} \mathrm{O}$ values at all surfactant concentrations (Figure 2). Increasing the concentration of the amphiphiles did not have any significant effect except in the case of CHAPS at the highest concentration (4\%, w/w protein) (Figure 2) for all proteins.

Effect of the surfactants on contribution of H-bonding on $\theta$ of BSA was dramatically different compared to FAF-BSA for all surfactants except SDS which caused a significant reduction in $\theta-\mathrm{H}_{2} \mathrm{O}$ in all proteins (Figure 2). This is understandable since SDS is known to be a strong denaturant of proteins [18]. The $\theta-\mathrm{H}_{2} \mathrm{O}$ of the BSA control was $37.3^{\circ}$ which is close to $10^{\circ}$ less than that of FAF-BSA. CHAPS increased $\theta-\mathrm{H}_{2} \mathrm{O}$ of BSA significantly at $2 \%(\mathrm{w} / \mathrm{w})$ to $41^{\circ}$. The contribution of H-bonding to surface energy was the highest when Z8 was used; it was increased significantly to $47^{\circ}, 44.7^{\circ}$, and $42^{\circ}$, at $1 \%, 2 \%$ and $4 \%(\mathrm{w} / \mathrm{w})$ of surfactant concentration.

In $\beta$-LGA, propensity for molecular structuring of water through $\mathrm{H}$-bonding by $\mathrm{Z} 8$ was the highest among all three proteins (Figure 2). The $\theta-\mathrm{H}_{2} \mathrm{O}$ increased $55 \%$ when only $1 \%$ of $\mathrm{Z8}$ was added. All other surfactants caused similar changes in the $\theta-\mathrm{H}_{2} \mathrm{O}$ of $\beta$-LGA as they did for BSA.

However, when $\alpha$ - $\mathrm{BrN}$ was used to observe the contribution of $\varphi$-interactions to the surface energy, all surfactants except Z12 significantly increased $\theta-\alpha-\mathrm{BrN}$ of the FAF-BSA dispersion (Figure 3). The increase as a percentage of the control $\theta-\alpha-\mathrm{BrN}$ valueat $1 \%$ (w/w protein) usage level was the highest for the zwitterionic CHAPS and followed the order; CHAPS (56\%) > TDTM (28\%) > TX100 (25\%) > SDS (19\%) > Z8 (17\%). On the contrary, zwitterionic Z12 significantly decreased $\theta-\alpha$-BrN of FAF-BSA by $50 \%$, $56 \%$, and $60.5 \%$ at $1 \%$, $2 \%$ and $4 \%(\mathrm{w} / \mathrm{w})$ usage level, respectively. In the case of BSA, the same level of surfactant usage resulted in a different solution behavior in that CHAPS, TDTM and SDS decreased $\theta-\alpha$-BrN instead of enhancing it (Figure 3). The $\theta-\alpha$-BrN of BSA was enhanced equally by nonionic TX100 and zwitterionic Z8 (38\%) followed by SDS 


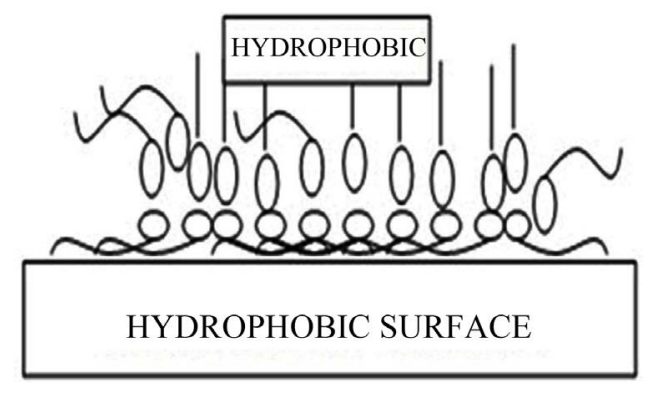

Figure 4. Postulated polar-head to polar-head bilayer orientation of surfactants on hydrophobized surface.

(6\%). As with FAF-BSA, Z12 decreased $\theta-\alpha$-BrN of BSA significantly by $29 \%, 40 \%$ and $65 \%$ at $1 \%$, $2 \%$ and $4 \%$ surfactant usage levels.

Data indicate significant changes in the way BSA performed in the presence of surfactants compared to FAF-BSA. SDS, which is known to bring about conformational change of BSA [19], significantly increased $\theta-\alpha$-BrN of FAF-BSA ( $56 \%$ at $2 \%$, w/w usage level) and, conversely, decreased it by $10 \%$ at the same level of usage in BSA. This reflected structural alteration of the FAF-BSA, resulting in exposure of hydrophobic residues, as a consequence of the delipidation process. Binding to fatty acids brings about structural changes of BSA [20].

Overall, $\beta$-LGA gave the lowest $\theta-\alpha$-BrN measurements regardless of the surfactants used. The nil control showed a small value of $10^{\circ}$ (Figure 3 ). This indicated reduced hydrocarbon-aqueous interface in spite of its hydrophobic cleft [21]. We reported heightened association tendency of $\beta$-LGA in the presence of zwitterionic amphiphiles and peptides [22]. Association decreases hydrocarbon-aqueous interface. Decreases in $\theta-\alpha-\mathrm{BrN}$ were seen at $1 \%(\mathrm{w} / \mathrm{w})$ surfactant usage level for all surfactants except for in the order; Z12 $(37 \%)>$ SDS $(30 \%)>$ Z8 27\%) > TDTM (10\%). Conversely, TX100 enhanced contribution of $\varphi$-interactions (10\%). Here too, the highly soap-like Z12 decreased $\varphi$-interactions most. At $4 \%$ usage level, it decreased the $\varphi$-interactions in $\beta$-LGA dispersion by $50 \%$.

Note that the three zwitterionic surfactants Z8, Z12 and CHAPS, acted differently even though charge was the same (Figure 1). The most dramatic difference was between Z8 and Z12; two sulfobetaines of exactly the same structure except for 4 carbon chain length difference in the alkane chain [23]. Whereas, Z8 had a caproic chain as the apolar tail, Z12 had a lauryl residue. Notably, Z8 increased both H-bonding and $\varphi$-interactions in BSA and FAF-BSA. On the other hand, Z12 decreased both significantly as a function of concentration (Figure 2 and Figure 3). CHAPS has the same N-alkyl sulfobetaine structure and same head group $\left(\mathrm{SO}_{3}\right)$ (Figure 1). In addition, it combines the aromatic features of bile salt at the end of its apolar tail. Though not as marked, it had an effect that was similar to Z8.

Tetrahedrally coordinated water molecules link via H-bonds around hydrophobic surfaces. This is referred to as "hydrophobic hydration" and it is entropically unfavorable since it disrupts existing structure and forms new and more ordered structure on the surrounding water molecules [24]. The free energy of transfer of hydrophobic ligand is approximately proportional to surface area of the ligand and is roughly determined by exposed non-H-bonding area [24]. It is plausible that increase in the $\theta-\mathrm{H}_{2} \mathrm{O}$ of all proteins by $\mathrm{Z} 8$ was due to exposed alkane residues that compelled water structuring and decreased system entropy. The critical micelle concentration (CMC) of Z8 is about 100 fold more (330 mM compared to 2 - $4 \mathrm{mM}$ ) than that of Z12. Therefore, Z8 was more likely to be predominantly in the monomeric form increasing its chances for interaction with proteins compared to the easily micellized Z12 which has an aggregation number of 55 . Thus, approximately 50 fold more Z8 molecules were available to coat the proteins and interface compared to Z12 assuming complete micellization of the later. The CMC range or value of CHAPS, TX100, SDS, and TDTM is $6-16,0.2-0.9,7-10$, and $4.5 \mathrm{mM}$, respectively (data provided by manufacturers).

Addition of surface active agent to water may decrease its wetting power, i.e., increase $\theta$, when adsorption of the surfactant at the solid-liquid interface occurs in such fashion that the amphipathic surfactant molecules form polar-head to polar-head bilayers on the hydrophobic surface (Figure 4). This would hypothetically orient their hydrophobic tails toward solvent molecules. In another study, we observed that at $22^{\circ} \mathrm{C}, \beta$-lactoglobulin asso- 
ciated in the presence of trace peptides to give a large aggregate distribution [25].

\section{Conclusion}

In conclusion, $\beta$-LGA in presence of Z8 showed the greatest increase in H-bonding with a concurrent decrease in $\varphi$-interactions. This conceivably reflected a large distribution of particles that resulted in increased water structuring around these surfactant particles. The next paper in this series investigates the effect of the same surfactants on the surface energy and emulsifying properties of the proteins.

\section{Acknowledgements}

Approved as journal article \#12697of the Mississippi Agricultural and Forestry Experiment Station, Mississippi State University, MS 39762. Research was completed as part of the Miss. Agric. \& For. Exp. Sta. Project No. MIS 352021. Funding was also from USDA ARS Mississippi Center for Food Safety and Post-Harvest Technology (SCA 58-6402-7-230). No. MIS 352021.

\section{References}

[1] Akiyoshi, K. (2002) Hydrophobic Effects. Supramolecular Design for Biological Applications, Fla CRC Press LLC., Boca Raton, 13-24.

[2] Walstra, P. and Dickinson, E. (1987) Overview of Emulsions and Foam Stability. Food Emulsions and Foams. Proc. International Symposium, Leeds, 24-26 March 1986, 242-258.

[3] Norde, W. (1995) Adsorption of Proteins at Solid-Liquid Interfaces. Cells and Materials, 5, 97-112.

[4] Britt, D.W., Jogikalmath, G. and Hlady, V. (2003) Protein Interactions with Monolayers at the Air-Water-Interface. Surfactant Science Series, 110, 415-434.

[5] Bohoua, G.L. and Haque, Z.U. (2007) Surface Activity of Surfactants and Dairy Proteins. Milchwissenschaft, 62, 394397.

[6] Krishnan, A., Liu, Y.-H., Cha, P., Allara, D. and Vogler, E.A. (2006) Interfacial Energetics of Globular-Blood Protein Adsorption to a Hydrophobic Interface from Aqueous-Buffer Solution. Interface, 3, 283-301. http://dx.doi.org/10.1098/rsif.2005.0087

[7] Omenyi, S.N., Snyder, R.S., Van Oss, C.J., Absolom, D.R. and Neumann, A.W. (1981) Effects of Zero van der Waals and Zero Electrostatic Forces on Droplet Sedimentation. Journal of Colloid and Interface Science, 81, 402-409. http://dx.doi.org/10.1016/0021-9797(81)90422-7

[8] Van Oss, C.J., Absolom, D.R., Grossberg, A.L. and Neumann, A.W. (1979) The Role of Van der Waals Forces and Hydrogen Bonds in "Hydrophobic Interactions” between Biopolymers and Low Energy Surfaces. Immunological Communications, 8, 11-29.

[9] Van Oss, C.J., Good, R.J. and Chaudhury, M.K. (1986) The Role of van der Waals Forces and Hydrogen Bonds in "Hydrophobic Interactions" between Biopolymers and Low Energy Surfaces. Journal of Colloid and Interface Science, 111, 378-390. http://dx.doi.org/10.1016/0021-9797(86)90041-X

[10] Young, T. (1805) An Essay on the Cohesion of Fluids. Philosophical Transactions of the Royal Society London, 85, 65-87. http://dx.doi.org/10.1098/rstl.1805.0005

[11] Holt, C. and Sawyer, L. (2003) The Principal Bovine Whey Protein b-Lactoglobulin: A Structure-Function Analysis. Progress in Biotechnology, 23, 44-49, 79-80.

[12] Hill, J.P., Boland, M.J., Creamer, L.K., Anema, S.G., Otter, D.E., Paterson, G.R., et al. (1996) Effect of the Bovine $\beta$-Lactoglobulin Phenotype on the Properties of $\beta$-Lactoglobulin, Milk Composition, and Dairy Products. In: Parris, N., Kato, A., Creamer, L.K. and Pearce, J., Eds., Macromolecular Interactions in Food Technology, ACS Symposium Series, Vol. 650, American Chemical Society, Washington DC, 281-294.

[13] Gottschalk, M., Nilsson, H., Roos, H. and Halle, B. (2003) Protein Self-Association in Solution: The Bovine $\beta$-Lactoglobulin Dimer and Octamer. Protein Science, 12, 2404-2411. http://dx.doi.org/10.1110/ps.0305903

[14] Haque, Z. and Kinsella, J.E. (1988) Emulsifying Properties of Food Proteins: Bovine Serum Albumin. Journal of Food Science, 53, 416-420. http://dx.doi.org/10.1111/j.1365-2621.1988.tb07719.x

[15] Haque, Z.Z. and Bohoua, G.L. (2015) Influence of Small Amphiphiles on Aqueous Dispersions of $\beta$-Lactoglobulin A and Bovine Serum Albumin: (2) Surface Energy and Emulsifying Properties. Food and Nutrition Science, 6.

[16] Petersen, R.G. (1985) Design and Analysis of Experiments. Marcel Dekker, Inc., New York.

[17] SAS Institute, Inc. (1985) SAS/STAT Guide for Personal Computers. 6th Edition, SAS Institute, Cary. 
[18] Rafati, A.A., Gharibi, H. and Iloukhani, H. (2003) Conformational Stability of Bovine Serum Albumin by Cationic Surfactant Treatments. Physics and Chemistry of Liquids, 41, 509-517. http://dx.doi.org/10.1080/00319100310001604867

[19] Takeda, K. and Moriyama, Y. (1997) The Interaction of Bovine Serum Albumin with Sodium Dodecyl Sulfate: Binding of the Surfactant and Conformational Change of the Protein Induced by the Binding. Current Topics in Colloid \& Interface Science, 1, 109-135.

[20] Saito, M., Ogasawara, M., Nasu, K., Monma, M. and Chikuni, K. (1995) Emulsifying Activity and Structural Stability of Fatty Acid-Bound Bovine Serum Albumin. Nippon Shokuhin Kagaku Kogaku Kaishi, 42, 155-162. http://dx.doi.org/10.3136/nskkk.42.155

[21] Sawyer, L., Brownlow, S., Polikarpov, I. and Wu, S.-Y. (1998) $\beta$-Lactoglobulin: Structural Studies, Biological Clues. International Dairy Journal, 8, 65-72. http://dx.doi.org/10.1016/S0958-6946(98)00021-1

[22] Haque, Z.U. and Mozaffar, Z. (1993) Influence of a Dipeptide, Aspartame, on Acetylcholinesterase Activity in the Mouse Brain. Bioscience, Biotechnology, and Biochemistry, 57, 689-690. http://dx.doi.org/10.1271/bbb.57.689

[23] Gonenne, A. and Ernst, R. (1978) Solubilization of Membrane Proteins by Sulfobetaines, Novel Zwitterionic Surfactants. Analytical Biochemistry, 87, 28-32. http://dx.doi.org/10.1016/0003-2697(78)90565-1

[24] Israelichvile, J.N. (1985) Intermolecular and Surface Forces with Applications to Colloidal and Biological Systems. Academic Press, London.

[25] Haque, Z.U. and Sharma, M. (2002) Influence of Cation Sequestering and pH on Quiescent Thermal Association of .BETA.-Lacto-Globulin NB from Fresh Cheddar Whey: An Insight into Gelation Mechanism. Food Science and Technology Research, 8, 311-316. http://dx.doi.org/10.3136/fstr.8.311

\section{Abbreviations}

Bovine serum albumin: BSA

$\alpha$-Bromonaphtalene: $\alpha$-BrN

Contact angle: $\theta$

3[(3 Cholaminodopropyl) dimethyl ammonio]-1 propane sulfonate: CHAPS

Emulsifying activity index: EAI

Emulsion stability: ES

Fatty acid free BSA: FAF-BSA

$\beta$-Lactoglobulin (variant A): $\beta$-LGA

N-octyl-N,N-dimethyl-3-ammonio-1-propanesulfonate: Z8

N-dodecyl-N, N dimethyl-3 ammonio-1 propane sulfonate: Z12

Polyoxyethylene glycol tert-octylphenyl ether: TX-100

Silane: $\Gamma$-Methacryloxypropyltrimethoxysilane

Sodium dodecyl sulfate: SDS

Surface energy: $\gamma$

Surface activity: SA

Solid-liquid interface: SL

Tetradecyltrimethylammonium-bromide: TDTM 